\title{
Radiofrequency ablation for chronic low back pain: A systematic review of randomized controlled trials
}

\author{
Laura E Leggett MSc ${ }^{1,3}$, Lesley JJ Soril MSc ${ }^{1,3}$, Diane L Lorenzetti MLS ${ }^{1,2}$, Tom Noseworthy MD MSc ${ }^{1,3}$, \\ Rodney Steadman MSc ${ }^{1,3}$, Simrandeep Tiwana $\mathrm{PhD}^{1,3}$, Fiona Clement $\mathrm{PhD}^{1,3}$
}

\begin{abstract}
LE Leggett, LJJ Soril, DL Lorenzetti, et al. Radiofrequency ablation for chronic low back pain: A systematic review of randomized controlled trials. Pain Res Manag 2014;19(5):e146-e153.
\end{abstract}

BACKGROUND: Radiofrequency ablation (RFA), a procedure using heat to interrupt pain signals in spinal nerves, is an emerging treatment option for chronic low back pain. Its clinical efficacy has not yet been established.

OBJECTIVE: To determine the efficacy of RFA for chronic low back pain associated with lumbar facet joints, sacroiliac joints, discogenic low back pain and the coccyx.

METHODS: A systematic review was conducted. Medline, EMBASE, PubMed, SPORTDiscus, CINAHL and the Cochrane Library were searched up to August 2013. Abstracts and full-text articles were reviewed in duplicate. Included articles were sham-controlled randomized controlled trials (RCTs), assessed the efficacy of RFA, reported at least one month of follow-up and included participants who had experienced back pain for at least three months. Data were extracted in duplicate and quality was assessed using the Cochrane Risk of Bias tool. Due to heterogeneity, as well as a lack of reported mean differences and SDs, meta-analysis was not possible using these data.

RESULTS: The present systematic review retrieved 1063 abstracts. Eleven sham-controlled RCTs were included: three studies involving discogenic back pain; six studies involving lumbar facet joint pain; and two studies involving sacroiliac joint pain. No studies were identified assessing the coccyx. The evidence supports RFA as an efficacious treatment for lumbar facet joint and sacroiliac joint pain, with five of six and both of the RCTs demonstrating statistically significant pain reductions, respectively. The evidence supporting RFA for the treatment of discogenic pain is mixed.

CONCLUSIONS: While the majority of the studies focusing on lumbar facet joints and sacroiliac joints suggest that RFA significantly reduces pain in short-term follow-up, the evidence base for discogenic low back pain is mixed. There is no RCT evidence for RFA for the coccyx. Future studies should examine the clinical significance of the achieved pain reduction and the long-term efficacy of RFA.

Key Words: Chronic low back pain; Low back pain; Radiofrequency ablation; Visual analogue scale

$\mathrm{M}$ ore than $80 \%$ of the global population will experience low back pain at least once in their life (1). At any one time, it is prevalent in $4 \%$ to $33 \%$ of the population (2). One-half of the adult population in the United States report having experienced low back pain within the previous year, and one-quarter report experiencing low back pain in the previous three months (3). Low back pain is responsible for significant resource utilization; it has been estimated that this condition costs more than $\$ 100$ billion per year in the United States, primarily due to lost productivity and wages (4).

Low back pain can originate from the lumbar facet joints, the sacroiliac joint, the intervertebral discs (discogenic low back pain) and the coccyx. While there is no standardized definition (5), chronic low back pain is typically defined as pain in the low back that persists for

\section{L'ablation par radiofréquence pour soulager les douleurs lombaires chroniques : une analyse systématique d'essais aléatoires et contrôlés}

HISTORIQUE : L'ablation par radiofréquence (ARF), une intervention faisant appel à la chaleur pour interrompre les signaux de douleur dans les nerfs rachidiens, est un traitement émergent dont l'efficacité n'est pas encore établie pour soulager les douleurs lombaires chroniques.

OBJECTIF : Déterminer l'efficacité de l'ARF pour soulager les douleurs lombaires chroniques associées aux facettes articulaires lombaires, aux articulations sacro-iliaques, aux articulations discales et au coccyx.

MÉTHODOLOGIE : Les chercheurs ont effectué une analyse systématique dans Medline, EMBASE, PubMed, SPORTDiscus, CINAHL et la Bibliothèque Cochrane jusqu'en août 2013. Ils ont examiné deux fois les résumés et les articles intégraux. Ils ont inclus les essais aléatoires et contrôlés (EAC) contre placebo, évalué l'efficacité de l'ARF, rendu compte d'au moins un mois de suivi et inclus les participants qui avaient souffert de douleurs lombaires pendant au moins trois mois. Ils ont extrait les données deux fois et évalué la qualité au moyen de l'outil de risque de biais de Cochrane. En raison de l'hétérogénéité et du manque de différences moyennes et d'ÉT déclarés, il n'a pas été possible d'effectuer de métaanalyse.

RÉSULTATS : La présente analyse systématique a permis d'extraire 1063 résumés. Onze EAC contre placebo ont été conservés : trois sur les douleurs aux articulations discales dorsales, six sur les douleurs aux facettes articulaires lombaires et deux sur les articulations sacro-iliaques. Aucune ne portait sur le coccyx. Cinq des six EAC sur les facettes articulaires lombaires et les deux EAC sur les articulations sacro-iliaques démontraient une réduction statistiquement significative de la douleur grâce à l'ARF. Les données probantes en appui à l'ARF pour traiter les douleurs discales sont mitigées. CONCLUSIONS : D'après la majorité des études sur les facettes articulaires lombaires et les articulations sacro-iliaques, l'ARF réduit considérablement la douleur au suivi à court terme, mais les données probantes sont mitigées à l'égard des douleurs des disques lombaires. Aucun EAC ne présente de résultats sur l'ARF appliqué au coccyx. D'autres études devraient porter sur l'importance clinique de la réduction de la douleur obtenue et sur l'efficacité à long terme de l'ARF.

$\geq 3$ months, while acute low back pain is typically defined as pain lasting for $<3$ months (6). Of the population with acute low back pain, approximately $2 \%$ to $34 \%$ will eventually experience chronic low back pain (7).

Conservative treatment options for chronic low back pain may include pharmaceuticals, manual therapy (eg, massage, physiotherapy, spinal manipulation), exercise therapy (eg, aerobic activity, muscle strengthening), and educational or psychological therapies (eg, cognitive behavioural therapy, support groups, educational sessions) $(8,9)$. A systematic review of randomized controlled trials, which assessed conservative treatment options for low back pain, found strong evidence for the use of muscle relaxants, manipulation, education ('back school') and exercise therapy (10). If conservative treatments are unsuccessful, more

\footnotetext{
${ }^{1}$ The Department Community Health Sciences, Teaching Research and Wellness Building, Calgary; ${ }^{2}$ Institute of Health Economics, Edmonton;

${ }^{3}$ Institute for Public Health, Teaching Research and Wellness Building, Calgary, Alberta

Correspondence: Dr Fiona Clement, 3D18, Teaching Research and Wellness Building, 3280 Hospital Drive Northwest, Calgary,

Alberta T2N 4N1. Telephone 403-210-9373, fax 403-270-7307, e-mail fclement@ucalgary.ca
} 
TABLE 1

\section{Inclusion and exclusion criteria}

\begin{tabular}{|c|c|}
\hline Inclusion criteria & Exclusion criteria \\
\hline $\begin{array}{l}\text { Pulsed or continuous radiofrequency } \\
\text { ablation }\end{array}$ & $\begin{array}{l}\text { Not radiofrequency ablation } \\
\text { technology }\end{array}$ \\
\hline Sham-controlled RCT & Not sham-controlled RCT design \\
\hline Original data & Animals \\
\hline Adult population & Nonoriginal data \\
\hline \multirow{4}{*}{$\begin{array}{l}\text { Pain persistent for } \geq 3 \text { months before } \\
\text { intervention } \\
\geq 1 \text { month follow-up reporting using } \\
\text { either a visual analogue scale or a } \\
\text { numerical rating scale }\end{array}$} & Pediatric population \\
\hline & Pain persistent for $<3$ months before \\
\hline & intervention \\
\hline & $\begin{array}{l}\text { Research only available in poster or } \\
\text { abstract form }\end{array}$ \\
\hline
\end{tabular}

RCT Randomized controlled trial

invasive methods, such as steroid injections, nerve blocks, cryoablation, radiofrequency ablation (RFA) or surgery, can be attempted (11).

First used to treat low back pain by Shealy (12) in 1975, RFA is a procedure that may offer low back pain relief for patients without a known pathology (infection, tumour, fracture or osteoporosis). During the procedure, a high-frequency electrical current runs through an insulated needle. At the tip of the needle, the electric field causes molecule movement which, in turn, produces thermal energy. The heat from the tip of the RFA device is targeted to create a small lesion within a nerve, which disrupts the pain signal. Numerous randomized controlled trials (RCTs) and observational studies have been completed assessing the ability of RFA to treat low back pain.

To our knowledge, there is no current systematic review on RFA that summarizes the available evidence to determine the efficacy of RFA for all four clinical conditions associated with chronic low back pain. Therefore, the objective of the present study is to determine the efficacy of RFA for the treatment of chronic low back pain associated with the lumbar facet joints, the sacroiliac joint, discogenic low back pain and the coccyx.

\section{METHODS}

A systematic review was completed. Medline, EMBASE, PubMed, SPORTDiscus, CINAHL and the Cochrane Central Registry of Controlled Trials (CENTRAL), Cochrane Database of Systematic Reviews, and University of York Centre for Reviews and Dissemination Databases were searched from inception to August 2013. Terms aimed at capturing the target diagnosis, such as "low back pain" and "back pain" were combined using the Boolean operator "or". These terms were then combined, using the Boolean operator "and", with terms describing the technology, such as "radiofrequency", "radio-frequency", "medial branch", "RF", "ablation" and "denervation". Results were limited to human studies and RCT designs. No other limitations were used. Details of the search are available from the authors on request.

All abstracts were screened in duplicate. Abstracts proceeded to full-text review if they: reported original data; were a sham-controlled RCT study design; assessed the efficacy of RFA; included adult participants with low back pain for $>3$ months before the intervention; and reported at least one month follow-up data using a visual analogue scale or numerical rating scale (Table 1). Abstracts were excluded if they failed to meet the criteria above or if they included animals, reported nonoriginal data or included pediatric populations. There were no restrictions on the type (cooled, pulsed or continuous), temperature or duration of RFA used. Abstracts selected for inclusion by either reviewer proceeded to full-text review. This initial abstract screen was intentionally broad to ensure that all relevant literature was captured.

Studies included after abstract review proceeded to full-text review in duplicate. Studies were included in the present review if they met all inclusion criteria and failed to meet any of the exclusion criteria presented in Table 1. Any discrepancy between reviewers during fulltext review was resolved through discussion and consensus. Reference

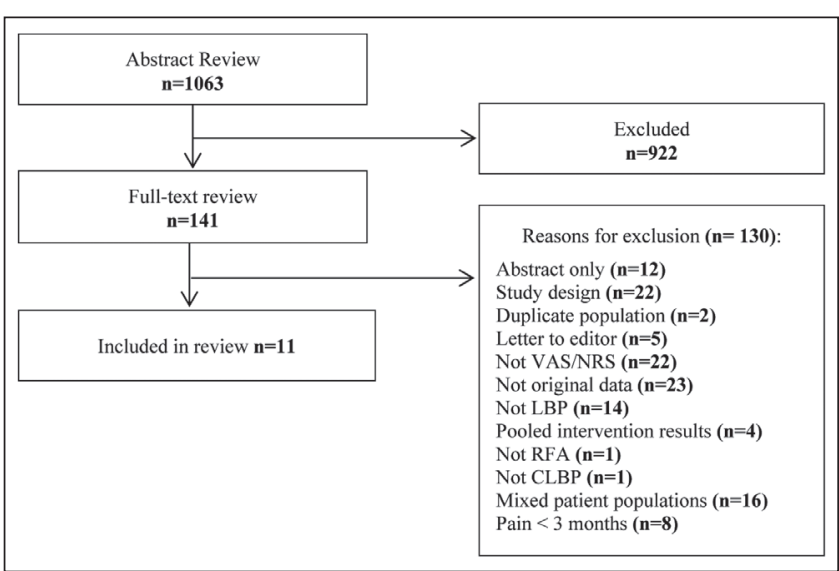

Figure 1) Flow chart of included and excluded studies. CLBP Chronic low back pain (LBP); NRS Numerical rating scale; RFA Radiofrequency ablation; VAS Visual analogue scale

lists of included studies were hand-searched to ensure all relevant studies were captured in the literature search.

For all studies, patient selection, study inclusion and exclusion criteria, patient characteristics, procedure protocol and outcomes measured were extracted using standardized data extraction forms. Pain outcomes (mean and SD) for intervention and control groups, as measured by visual analogue or numerical rating scales, were also extracted from each study.

During data extraction, each included study was assessed for quality using the Cochrane Risk of Bias Checklist (13). Using this checklist, each included study was assessed for seven areas of bias (random assignment generation; allocation concealment; blinding of participants and personnel; blinding of outcome assessment; incomplete outcome data; selective reporting; and any additional potential sources of bias) (13). Each of these seven potential areas of bias were assigned a 'low', 'high' or 'unclear' risk of bias (13). Quality assessment was completed in duplicate, with discrepancies being resolved through discussion and consensus.

\section{RESULTS}

The literature search identified 1063 abstracts (Figure 1). Of these, 922 were excluded during abstract review and 141 proceeded to fulltext review. During full-text review, an additional 130 studies were excluded. A total of 11 studies met the inclusion criteria when assessed during full-text review and were included in the present systematic review (14-24). Hand-searching the references of the 11 included studies did not identify any additional articles.

The final 11 studies were allocated into three categories based on location of low back pain: discogenic low back pain $(14,17,18)$; lumbar facet joint pain $(16,19,20,22-24)$; and sacroiliac back pain $(15,21)$ (Table 2). No RCTs addressing the efficacy of RFA for treating pain in the coccyx region were found in the literature.

The number of participants in each study ranged from 20 (18) to 81 (23). In the control groups, the mean age ranged from 38.4 years (17) to 64 years (21), and in the intervention groups, the mean age ranged from 40.4 years (17) to 59.6 years (22). Three studies were from the United States $(15,17,21)$, three from the Netherlands $(14,23,24)$, and the remaining were from Norway (18), Canada (19), Sweden (20), United Kingdom (16) and Turkey (22).

Of the included studies, seven used a visual analogue scale to measure reduction in pain $(14,16,19,20,22-24)$, three used a numerical rating scale $(15,17,21)$ and one used the Brief Pain Inventory (18). Studies measured pain outcomes at various times, with all studies measuring a baseline, or zero time point, and some recording outcomes up to one year later $(18,22)$. RFA procedure protocol varied within the included studies, with eight using conventional RFA (14,16,18-20,22$24)$ and three using cooled RFA (15,17,21). All of the included studies 
TABLE 2

Characteristics of randomized controlled trials reporting the efficacy of radiofrequency ablation (RFA)

Author
(reference),
year; country

Patient selection

Comparators

Outcomes

\section{Discogenic}

Barendse Patient selection: Patients were recruited from one teaching hospital between July 1994

et al (14), and September 1996. Participants were randomly assigned by a computer program to

2001; The receive the intervention or sham procedure

Netherlands Inclusion criteria: Chronic low back pain for $>1$ year, nonresponsive to conservative treatment, 30 to 65 years of age, positive response to discography

Exclusion criteria: Spinal stenosis, spondylolithesis, multilevel burnt out disc lesions, coagulation disturbances, pregnancy, diabetes mellitus, $>1$ pain syndrome

Patient characteristics: 13 participants ( 8 women and 5 men) with a mean age of $40.8 \pm 7.5$ years were randomly assigned to receive the intervention. 15 participants (10 women and 5 men) with a mean age of $45.2 \pm 8.4$ years were randomly assigned to receive the sham procedure. There were no statistically significant differences in patient characteristics between the sham and intervention groups

Kapural et al Patient selection: Patients were recruited from the authors' medical practices between

(17), 2013; September 2007 and October 2011. Participants were randomly assigned using a computer United program to receive either the intervention or sham procedure

States

Inclusion criteria: Age $\geq 18$ years, chronic low back pain for $>6$ months, resistant to conservative treatment, no surgery in the previous 3 months, response to discography, disc height $50 \%$ compared with adjacent disc

Exclusion criteria: Lumbar surgery, nucleus pulposus herniation, disc bulges $>5 \mathrm{~mm}$, free disc fragments, three or more discs degenerated on MRI, structural abnormality, compressive radiculopathy, cervical or thoracic pain, lumbar canal stenosis, chronic sever conditions, immunosuppression, history of coagulopathy, neurological deficits, traumatic spinal fracture, workers compensation, psychological issues, pregnancy, infection, allergies to medication used, body mass index $>30 \mathrm{~kg} / \mathrm{m}^{2}$

Patient characteristics: 27 participants (15 women and 12 men) with a mean age of $40.4 \pm 10.3$ years were randomly assigned to receive the intervention. 30 participants ( 15 women and 15 men) with a mean age of $38.4 \pm 10.4$ years were randomly assigned to receive the sham procedure. There were no statistically significant differences in patient characteristics between the sham and intervention groups

Kvarstein Patient selection: Patients were recruited between August 2003 and January 2006 based et al (18), on referrals. Participants were randomly assigned in 1:1 sex-stratified blocks, using 2009; random numbers

Norway Inclusion criteria: 20 to 65 years of age, back pain for $>6$ months, pain $>5$ on a NRS scale, pain worsened by sitting, no neurological deficits, no history of surgical interventions, no response to conservative treatment, disc degeneration, positive response to diagnostic discography

Exclusion criteria: Acute infection, history of drug abuse, psychological disorder that could affect outcome, abnormal neurological examination, radicular pain, spinal deformity, disc herniation $>4 \mathrm{~mm}$, pregnancy, allergy to medication used in procedure

Patient characteristics: 10 participants ( 7 women and 3 men) with a mean age of $44.7 \pm 10.1$ years were randomly assigned to receive the intervention. 10 participants ( 7 women and 3 men) with a mean age of $39.6 \pm 8.9$ years were randomly assigned to receive the sham procedure. There were no statistically significant differences in patient characteristics, pain duration or pain medication between the sham and intervention groups

\section{Lumbar facet}

Gallagher Patient selection: Not reported

et al (16), Inclusion criteria: Low back pain for >3 months, positive or neutral response to diagnostic 1994;

United

Kingdom block, 25 to 55 years of age, diagnosis of facet joint pain

Exclusion criteria: General ill health, pending compensation claims, mental illness or personality disorder, previous back operation

Patient characteristics: 24 participants were randomly assigned to receive the intervention (18 with good response to diagnostic blocks, 6 with poor response to diagnostic blocks) 17 were randomly assigned to receive the sham procedure (12 with good response to diagnostic blocks and 5 with poor response to diagnostic blocks). No patient characteristics were reported

Type of intervention: Continuous conventional RFA, with a 17-gauge cannula, for 240 s using a temperature of $50^{\circ} \mathrm{C}$ to $65^{\circ} \mathrm{C}$

Type of control: Sham procedure with the same placement as the intervention, but no current applied
Outcomes measured: VAS, Oswestry Disability Index, number of analgesic tablets taken, COOP/WONCA quality of life questionnaire, Impairment (Waddell)

Outcome ascertainment: Baseline, 2 months

Type of analysis: Intention-to-treat

Outcomes measured: Numerical rating scale, Oswestry Disability Index, health care utilization questionnaire, Short-Form 36 Health Survey

Outcome ascertainment:

Baseline, 1 month, 3 months, 6 months

Type of analysis: Not reported
Outcomes measured: Brief Pain Inventory, Short Form-36, Oswestry Disability Index, relative change in pain

Outcome ascertainment: Baseline, 6 months, 12 months

Type of analysis: Intention-to-treat and per-protocol
Type of intervention: Continuous conventional RFA, for 90 s using a temperature of $80^{\circ} \mathrm{C}$

Type of control: Sham procedure with the same placement as the intervention, but no current applied
Outcomes measured: VAS and McGill Pain Questionnaire

Outcome ascertainment: Baseline, 1 month, 6 months

Type of analysis: Not reported 
TABLE 2 - CONTINUED

Characteristics of randomized controlled trials reporting the efficacy of radiofrequency ablation (RFA)

\section{Author}

(reference),

year; country

Leclaire et al Patient selection: Patients were recruited from physiatrist referral between October 1993

(19), 2001; and December 1996. Participants were randomly assigned in blocks of four

Canada Inclusion criteria: 18 to 65 years of age, relief from intra-articular facet injections Exclusion criteria: Allergy to medications used in procedure, blood coagulation disorder, cardiac pace-maker, sciatic pain, low back pain not related to mechanical disorder, previous back surgery

Patient characteristics: 36 participants (24 women and 12 men) with a mean age of $46.7 \pm 9.3$ years were randomly assigned to receive the intervention. 34 participants (21 women and 13 men) with a mean age of $46.4 \pm 9.7$ years were randomly assigned to receive the sham procedure. There were no statistically significant differences in patient characteristics between the sham and intervention groups

Nath et al Patient selection: Not reported

(20), 2008; Inclusion criteria: Back pain for >2 years, no response to conservative treatment, positive

Sweden response to diagnostic block

Exclusion criteria: Pregnancy, coagulopathies, malignancy, infection, mental handicap, psychiatric disorder, patients living too far away to complete follow-up

Patient characteristics: 20 participants (14 women and 6 men) with a mean age of 56 years were randomly assigned to receive the intervention. 20 participants, 21 women and 13 men with a mean age of 53 years were randomly assigned to receive the sham procedure. There were no statistically significant differences in patient characteristics between the sham and intervention groups. However, the intervention group reported more generalized pain, low back pain, referred pain in the leg and had worse hip movement

Tekin et al Patient selection: Participants were randomly assigned using a random number generator.

(22), 2007; Inclusion criteria: >17 years of age, symptoms indicative of lumbar facet pain for

Turkey $>6$ months, no response to conservative treatment

Exclusion criteria: Allergy to medication used in procedure, blood coagulation disorder, language problems, pregnancy

Patient characteristics: 20 participants, 9 women and 11 men with a mean age of $60.5 \pm 8.5$ years, were randomly assigned to receive the continuous intervention. 20 participants ( 8 women and 12 men) with a mean age of $59.6 \pm 7.7$ years, were randomly assigned to receive the pulsed intervention. 20 participants, 9 women and 11 men with a mean age of $57.9 \pm 9.3$ years, were randomly assigned to receive the sham procedure. There were no statistically significant differences in patient characteristics between the sham and intervention groups

Van Kleef Patient selection: Patients who had been referred by a medical specialist to a pain et al (24), management centre due to lack of response to conservative therapies for low back pain 1999; The were recruited between June 1994 and April 1996

Netherlands Inclusion criteria: Chronic low back pain, no response to conservative therapy, positive response to diagnostic block

Exclusion criteria: Previous back surgery, known cause of back pain, diabetes mellitus, $>1$ pain syndrome

Patient characteristics: 15 participants (10 women and 5 men) with a mean age of $46.6 \pm 7.4$ years, were randomly assigned to receive the intervention. 16 participants (10 women and 6 men) with a mean age of $41.4 \pm 7.5$ years were randomly assigned to receive the sham procedure. There were no statistically significant differences in patient characteristics between the sham and intervention groups

Van Wijk et al Patient selection: Patients were recruited from 4 pain clinics between May 1996 and (23), 2005; January 1999

The Inclusion criteria: Older than 117, chronic low back pain for $>6$ months, no radicular Netherlands syndrome or indication for back surgery

Exclusion criteria: Prior RFA treatment, coagulation disturbances, allergies to medications used in procedure, language problems, malignancy, mental handicap, psychiatric condition, pregnancy

Patient characteristics: 40 participants (30 women and 10 men) with a mean age of $46.9 \pm 11.5$ years were randomly assigned to receive the intervention. 41 participants ( 28 women and 13 men) with a mean age of $48.1 \pm 12.6$ years were randomly assigned to receive the sham procedure. There were no statistically significant differences in patient characteristics between the sham and intervention groups
Comparators
Type of intervention: Continuous conventional RFA, with a 22-gauge cannula and $5 \mathrm{~mm}$ tip length, for $90 \mathrm{~s}$ using a temperature of $80^{\circ} \mathrm{C}$

Type of control: Sham procedure with the same placement as the intervention, but no current applied

Type of intervention: Continuous conventional RFA, with a 22-gauge cannula and $5 \mathrm{~mm}$ tip length, for $60 \mathrm{~s}$ using a temperature of $85^{\circ} \mathrm{C}$ Type of control: Sham procedure with the same placement as the intervention, but no current applied

\section{Outcomes}

Outcomes measured:

Roland-Morris

Questionnaire, Oswestry Scale, VAS, spinal mobility and strength, return to work

Outcome ascertainment:

Baseline, 3 months

Type of analysis:

Intention-to-treat

Outcomes measured:

Global perception of improvement, low back pain, lower limb pain and relief of generalized pain

Outcome ascertainment:

Baseline, 6 months

Type of analysis: Not reported

Type of intervention: Pulsed Outcomes measured: and continuous heated VAS, and Oswestry RFA, with a 22-gauge Disability Index cannula. Pulsed RFA used Outcome ascertainment: $2 \mathrm{~mm}$ tip length and a temperature of $42^{\circ} \mathrm{C}$ for 240 s. Continuous RFA used $10 \mathrm{~mm}$ tip length and a temperature of $80^{\circ} \mathrm{C}$ for $90 \mathrm{~s}$

Type of control: Sham procedure with the same placement as the intervention, but no current applied

Type of intervention: Continuous conventional RFA, with a 22-gauge cannula and $5 \mathrm{~mm}$ tip length, for $60 \mathrm{~s}$ using a temperature of $80^{\circ} \mathrm{C}$

Type of control: Sham procedure with the same placement as the intervention, but no current applied

Type of intervention: Continuous conventional RFA, with a 22-gauge cannula and $5 \mathrm{~mm}$ tip length, for $60 \mathrm{~s}$ using a temperature of $80^{\circ} \mathrm{C}$

Type of control: Sham procedure with the same placement as the intervention, but no current applied
Outcomes measured: VAS, global perceived effect, Impairment evaluation (Waddell), Oswestry Disability Index, and the COOPWONCA quality of life questionnaire

Outcome ascertainment: Baseline, 2 months

Type of analysis: Not reported

Outcomes measured: VAS, daily activities, analgesic intake, global perceived effect, Short Form-36 Health Survey, Zung Self Rating Depression Scale and Multidimensional

Pain Inventory

Outcome ascertainment:

Baseline, 3 months

Type of analysis: Not reported

Continued on next page 
TABLE 2 - CONTINUED

Characteristics of randomized controlled trials reporting the efficacy of radiofrequency ablation (RFA)

\section{Author}

(reference),

year; country

Patient selection

Comparators

Outcomes

Sacroiliac

Cohen et al Patient selection: Patients were recruited between May 2005 and August 2006, and

(15), 2008; randomly assigned in a 1:1 ratio, using blocks of 4

United Inclusion criteria: $>18$ years of age, pain for $\geq 6$ months, no response to conservative treat-

States ment, pain relief from sacroiliac joint injections

Exclusion criteria: Herniated disc, spondyloarthropathy, untreated coagulopathy, unstable medical or psychological illness

Patient characteristics: 14 participants ( 9 women and 5 men) with a mean age of $51.9 \pm 13.6$ years were randomly assigned to receive the intervention; 14 participants ( 8 women and 6 men) with a mean age of $51.8 \pm 13.1$ years were randomly assigned to receive the sham procedure. There were no statistically significant differences in patient characteristics between the sham and intervention groups, with the exception of military duty status, and baseline Oswestry Disability Index Scores

Patel et al Patient selection: Patients were recruited by the authors, the authors' colleagues and using Type of intervention: (21), 2012; advertisements between July 2008 and July 2010. Participants were randomly assigned in United a $2: 1$ ratio

States Inclusion criteria: Axial pain below the L5 vertebrae lasting $>6$ months, 3-day average NRS score rating between 4 and $8,>18$ years of age, no response to conservative treatment

Exclusion criteria: History of intervertebral disc disease or zygopophyseal joint pain, Beck's Depression Inventory score $>20$, psychological barriers to recovery, spinal pathology, infection, cervical or thoracic pain $>2 / 10$ on NRS, acute illness, pregnancy, radicular pain, immunosuppression, allergy to medications used, smokers, high narcotics use

Patient characteristics: 34 participants (23 women and 11 men) with a mean age of $56 \pm 13$ years, were randomly assigned to receive the intervention. 17 participants (14 women and 3 men) with a mean age of $64 \pm 14$ years, were randomly assigned to

Type of intervention: Continuous cooled RFA, with a 17-gauge cannula and $4 \mathrm{~mm}$ tip length, for $90 \mathrm{~s}$ using a temperature of $80^{\circ} \mathrm{C}$

Type of control: Sham procedure with the same placement as the intervention, but no current applied Continuous cooled RFA, with a 17-gauge cannula and $4 \mathrm{~mm}$ tip length, for 150 s using a temperature of $60^{\circ} \mathrm{C}$ Type of control: Sham procedure with the same placement as the intervention, but no current applied
Outcomes measured: Global perceived effect, NRS, Oswestry Disability Index Outcome ascertainment: Baseline, 1 month, 3 months, 6 months

Type of analysis: Not reported
Outcomes measured: NRS, Oswestry Disability Index, Short Form-36, bodily pain subscale and Short From-36 physical functioning subscale Outcome ascertainment: Baseline, 3 months, 6 months, 9 months Type of analysis: Not reported receive the sham procedure. There were no statistically significant differences in patient characteristics between the sham and intervention groups

CRF Continuous radiofrequency; MRI Magnetic resonance imaging; NR Not reported; NRS Numerical rating scale; VAS Visual analogue scale

used continuous RFA, with the exception of one study, which assessed the efficacy of both pulsed and continuous RFA (22).

Broadly, the included studies are of moderate to high quality as assessed by the Cochrane Risk of Bias (13) (Table 3). Only two studies were assessed as having a high risk of bias in one of the seven areas; Leclaire et al (19) had 'high' risk of bias in selective reporting (19), and Patel et al (21) had 'high' risk of bias in blinding of participants (21). All of the included studies used some type of randomization to allocate patients to either the sham or treatment arms. However, some did not report the method of randomization; therefore, it was not possible to assess random sequence generation in these studies. Five of the included studies did not report sufficient information for allocation concealment to be assessed $(14,16,20,22,24)$. Generally, blinding of participants, personnel and outcome assessors was clearly reported and with a low risk of bias. Because it is unknown whether other biases influenced the results of these studies, 'unclear risk of bias' was assigned to all under the final category 'other bias'.

Due to heterogeneity in outcome measures, location of pain and follow-up times, as well as a lack of reported mean differences and standard deviations, meta-analysis was not possible with these data. The results of the included studies are summarized in Table 4. A discussion of the key findings, according to area of pain, follows.

\section{Discogenic back pain}

Three studies assessed the use of RFA for treating discogenic back pain using a variety of methods. Two of the included studies used conventional RFA $(14,18)$ and one used cooled RFA (17). The study using cooled RFA, used a bipolar configuration which was then followed by the standard monopolar configuration (17).

All three studies used diagnostic discography to confirm diagnosis of discogenic low back pain, and only participants with a positive response to this procedure were included in the studies.
Studies used RFA at a temperature between $50^{\circ} \mathrm{C}$ and $70^{\circ} \mathrm{C}$ to create the lesion. The three studies reported that the characteristics of patients were not significantly different between the control and intervention groups, with the exception of Barendse et al (14), who reported that those in the intervention group had higher pain and had a longer duration of pain than the control group. Although all three studies used different outcome measures to assess change in pain, all used a 0 to 10 scale.

The two studies, Barendse et al (14) and Kvarstein et al (18), that assessed the efficacy of conventional RFA found no evidence of statistically significant benefit when the intervention group was compared with the control group. A study conducted by Kapural et al (17), which assessed the efficacy of cooled RFA, found evidence of a statistically significant benefit. This study reported a 2.19-point reduction in pain within the intervention group and a 0.6-point reduction in pain in the control group six months postprocedure $(\mathrm{P}=0.006)(17)$.

\section{Lumbar facet joint pain}

Six studies included in the present systematic review assessed the efficacy of RFA in reducing chronic lumbar facet back pain $(16,19,20,22$ 24). Five studies used continuous RFA $(16,19,20,23,24)$, and one used a combination of pulsed and continuous RFA (22). All six included studies used conventional RFA, and used diagnostic blocks to confirm diagnosis of lumbar facet joint pain $(16,19,20,22-24)$. Five of the six studies used 22-gauge cannulas $(19,20,22-24)$, and one study did not report these data (16). All six studies assessed pain reduction using a visual analogue scale; three used a 0 to 10 scale $(20,23,24)$, two used a 0 to 100 scale $(16,19)$ and one study did not report the scale used $(22)$. Five studies reported that there were no statistically significant differences in patient characteristics between the intervention and control groups at baseline $(16,19,22-24)$. Nath et al (20) reported that those who received RFA had more general pain, low back pain and referred pain than those in the control group. 


\begin{tabular}{|c|c|c|c|c|c|c|c|}
\hline & $\begin{array}{c}\text { Random } \\
\text { sequence } \\
\text { generation }\end{array}$ & $\begin{array}{c}\text { Allocation } \\
\text { concealment }\end{array}$ & $\begin{array}{c}\text { Blinding of } \\
\text { participants and } \\
\text { personnel }\end{array}$ & $\begin{array}{l}\text { Blinding of } \\
\text { outcome } \\
\text { assessment }\end{array}$ & $\begin{array}{l}\text { Incomplete } \\
\text { outcome data }\end{array}$ & $\begin{array}{l}\text { Selective } \\
\text { reporting }\end{array}$ & Other bias \\
\hline \multicolumn{8}{|l|}{ Discogenic } \\
\hline Barendse et al (14), 2001; The Netherlands & Low & Unclear & Low & Low & Low & Low & Low \\
\hline Kapural et al (17), 2013; United States & Low & Low & Low & Low & Low & Low & Low \\
\hline Kvarstein et al (18), 2009; Norway & Low & Low & Low & Low & Low & Low & Low \\
\hline \multicolumn{8}{|l|}{ Lumbar facet } \\
\hline Gallagher et al (16), 1994; United Kingdom & Unclear & Unclear & Unclear & Low & Unclear & Low & Unclear \\
\hline Leclaire et al (19), 2001; Canada & Unclear & Low & Low & Unclear & Low & High & Unclear \\
\hline Nath et al (20), 2008; Sweden & Low & Unclear & Low & Unclear & Unclear & Low & Low \\
\hline Tekin et al (22), 2007; Turkey & Low & Unclear & Low & Low & Low & Low & Low \\
\hline van Kleef et al (24), 1999; The Netherlands & Low & Unclear & Low & Low & Low & Low & Low \\
\hline van Wijk et al (23), 2005; The Netherlands & Low & Low & Low & Low & Low & Low & Low \\
\hline \multicolumn{8}{|l|}{ Sacroiliac } \\
\hline Cohen et al (15), 2008; United States & Low & Low & Unclear & Low & Low & Low & Low \\
\hline Patel et al (21), 2012; United States & Low & Low & High & Low & Low & Low & Low \\
\hline
\end{tabular}

Low, Unclear and High indicate risk of bias

Results from the included studies were mixed as to the efficacy of RFA. Five of the included studies found evidence of statistically significant reductions in pain when comparing RFA with sham (16,20,22-24). One of these studies found a significant effect only in participants who experienced a positive response to diagnostic block $(\mathrm{P}<0.05)$; for participants who experienced equivocal response to diagnostic blocks, statistically significant benefit was not found (16). One of the six included studies did not find any evidence of statistically significant improvement; this study found a 0.5 point reduction in pain within the intervention group and a 0.6 point reduction in pain in the control group (19).

\section{Sacroiliac joint pain}

Two studies assessed the efficacy of RFA for treating sacroiliac pain $(15,21)$. Both used continuous, cooled RFA procedures $(15,21)$. These studies used a 17-gauge cannula and a $4 \mathrm{~mm}$ tip length. Cohen et al (15) heated the device to $80^{\circ} \mathrm{C}$ for $90 \mathrm{~s}$, while Patel et al (21) used $60^{\circ} \mathrm{C}$ heat for $150 \mathrm{~s}$. Both studies used a numerical rating scale, with a range of 0 to 10 to assess change in pain. Cohen et al (15) followed participants for six months. Patel et al (21) followed participants for nine months postprocedure, but only presented data for the control group up to three months. Both of these studies reported that there were no statistically significant differences in patient characteristics at baseline between the intervention and controls groups.

These two studies assessing the efficacy of RFA for treating sacroiliac joint pain studies found statistically significant reduction in pain for the intervention group, when compared with the control group $(15,21)$. Three months postprocedure, Cohen et al (15) found a 3.7-point reduction in pain within the intervention group, while the control group experienced only a 0.5 -point reduction in pain. Three months postprocedure, Patel et al (21) found a 2.4-point pain reduction in the intervention group, and a 0.8 -point pain reduction in the control group.

\section{DISCUSSION}

Eleven sham-controlled RCTs were found, assessing the efficacy of RFA for discogenic back pain $(14,17,18)$, lumbar facet joint pain $(16,19,20,22-24)$ and sacroiliac joint pain $(15,21)$. There were no RCTs investigating the use of RFA for pain in the coccyx region found in the literature.

The efficacy of RFA for discogenic back pain remains unclear. Of the three included studies, two studies assessed conventional RFA and found no statistically significant benefit over sham at two (14) and 12 months (18), while one study assessed cooled RFA and did find a statistically significant benefit compared with sham (17). The contradicting results may be attributable to the procedural differences between these three studies. However, the clinical relevance of these findings is unclear.

Five of the six studies assessing RFA for treating lumbar facet joint pain found statistically significant results $(16,20,22-24)$, and one found no evidence of statistically significant benefit (19). The methods used in these studies were similar, with all using continuous, conventional RFA and diagnostic blocks to confirm diagnosis. This number of similar, high-quality sham-controlled RCTs on lumbar facet joints provides a robust evidence base that suggests that continuous, conventional RFA is efficacious in reducing lumbar facet joint pain. However, the longest follow-up time point within these studies was one year (22), with the majority of the studies only following patients for two (24), three $(19,23)$ or six months $(16,20)$. The long-term pain relief associated with RFA is unclear. In addition, the clinical relevance of the pain relief achieved is unknown. The studies reporting improvement reported modest reductions in pain scores with no predefined clinically relevant pain reduction reported. A large high-quality RCT in this patient population measuring predefined clinically meaningful pain reduction following patients for at least one year is now required to understand the efficacy of RFA for treating lumbar facet joint low back pain.

Both of the RCTs assessing the efficacy of RFA for treating sacroiliac joint pain found statistically significant reductions in pain for the treatment group compared with the control group $(15,21)$. The procedures used in these two studies were similar in that they both used continuous, cooled RFA $(15,21)$. These two studies suggest that continuous cooled RFA is efficacious in reducing sacroiliac joint pain; however, with only two available RCTs, more data on the efficacy of RFA for sacroiliac joint pain would strengthen this conclusion. In addition, as with the lumbar facet joint literature, the clinical significance of the modest pain reduction is unclear.

The lack of literature on the efficacy of RFA to treat the coccyx is surprising because this topic has been studied using non-RCT study designs (25). A sham-controlled RCT on the efficacy of RFA for the treatment of pain in the coccyx area would be a positive addition to the literature and could impact clinical practice.

The present systematic review had several limitations that merit comment, including limitations of the literature, inability to conduct a meta-analysis and using statistical significance as a surrogate for clinical significance.

As with all systematic reviews, the key limitation of the present review was that it reflects the literature and data available on this subject. In this case, the literature on sacroiliac joint pain was limited, the literature on discogenic pain used heterogeneous RFA methods and no literature was found on coccyx pain. This incomplete literature 
TABLE 4

Results of included studies

\begin{tabular}{|c|c|c|c|c|c|c|}
\hline $\begin{array}{l}\text { Author } \\
\text { (reference), } \\
\text { year; country }\end{array}$ & $\begin{array}{l}\text { Type of pain } \\
\text { outcome } \\
\text { measure }\end{array}$ & $\begin{array}{l}\text { Scale of } \\
\text { pain } \\
\text { outcome } \\
\text { measure }\end{array}$ & $\begin{array}{c}\text { Time after } \\
\text { RFA }\end{array}$ & $\begin{array}{l}\text { Intervention group } \\
\text { pain rating } \\
\text { (mean } \pm S D)\end{array}$ & $\begin{array}{l}\text { Control group } \\
\text { pain rating } \\
\text { (mean } \pm S D \text { ) }\end{array}$ & Findings \\
\hline \multicolumn{7}{|l|}{ Discogenic } \\
\hline $\begin{array}{l}\text { Barendse et al } \\
\text { (14), 2001; The } \\
\text { Netherlands }\end{array}$ & VAS & $0-10$ & $\begin{array}{l}\text { Baseline } \\
2 \text { months }\end{array}$ & $\begin{array}{c}6.5 \pm 1.3 \\
5.89\end{array}$ & $\begin{array}{c}5.5 \pm 1.1 \\
4.36\end{array}$ & No evidence of statistically significant benefit \\
\hline $\begin{array}{l}\text { Kapural et al } \\
(17), 2013 \text {; } \\
\text { USA }\end{array}$ & NRS & $0-10$ & $\begin{array}{l}\text { Baseline } \\
1 \text { month } \\
3 \text { months } \\
6 \text { months }\end{array}$ & $\begin{array}{l}7.13 \pm 1.61 \\
5.31 \pm 2.04 \\
4.94 \pm 2.05 \\
4.94 \pm 2.15\end{array}$ & $\begin{array}{l}7.18 \pm 1.98 \\
5.72 \pm 2.29 \\
5.98 \pm 2.36 \\
6.58 \pm 2.11\end{array}$ & $\begin{array}{l}\text { A statistically significant reduction in pain was found in } \\
\text { the intervention group, compared with the control group } \\
\text { six months after treatment }(P=0.006)\end{array}$ \\
\hline $\begin{array}{l}\text { Kvarstein et al } \\
\text { (18), 2009; } \\
\text { Norway }\end{array}$ & $\mathrm{BPI}$ & $0-10$ & $\begin{array}{l}\text { Baseline } \\
6 \text { months } \\
12 \text { months }\end{array}$ & $\begin{array}{l}4.6 \pm 1.8 \\
3.7 \pm 2.2 \\
3.2 \pm 2.3\end{array}$ & $\begin{array}{c}5.5 \pm 2 \\
5.3 \pm 1.8 \\
4.9 \pm 2.1\end{array}$ & No evidence of statistically significant benefit \\
\hline Lumbar facet & & & & & & \\
\hline $\begin{array}{l}\text { Gallagher et al } \\
(16), 1994 ; \\
\text { United } \\
\text { Kingdom }\end{array}$ & VAS & $0-100$ & $\begin{array}{l}\text { Baseline } \\
1 \text { month } \\
6 \text { months }\end{array}$ & $\begin{array}{l}58 \pm 4.2 \\
34 \pm 6.9 \\
44 \pm 7.2\end{array}$ & $\begin{array}{l}72 \pm 5.6 \\
60 \pm 9.8 \\
70 \pm 8.5\end{array}$ & $\begin{array}{l}\text { For participants who experienced good response to } \\
\text { diagnostic blocks: a statistically significant reduction in } \\
\text { pain was found in the intervention group, compared with } \\
\text { the control group six months after treatment }(P<0.05)\end{array}$ \\
\hline $\begin{array}{l}\text { Leclaire et al } \\
\qquad(19), 2001 ; \\
\text { Canada }\end{array}$ & VAS & $0-100$ & $\begin{array}{l}\text { Baseline } \\
3 \text { months }\end{array}$ & $\begin{array}{l}51.9 \\
52.3\end{array}$ & $\begin{array}{l}51.5 \\
44.4\end{array}$ & No evidence of statistically significant benefit \\
\hline $\begin{array}{l}\text { Nath et al (20), } \\
\text { Sweden 2008; }\end{array}$ & VAS & $0-10$ & $\begin{array}{l}\text { Baseline } \\
6 \text { months }\end{array}$ & $\begin{array}{l}5.98 \\
3.88\end{array}$ & $\begin{array}{l}4.38 \\
3.68\end{array}$ & $\begin{array}{l}\text { A statistically significant reduction in pain was found in } \\
\text { the intervention group, compared with the control group } \\
\text { six months after treatment }(P=0.004)\end{array}$ \\
\hline $\begin{array}{c}\text { Tekin (22), et al } \\
\text { 2007; Turkey }\end{array}$ & VAS & NR & $\begin{array}{l}\text { Baseline } \\
6 \text { months }\end{array}$ & $\begin{array}{l}\text { PRF: } 6.6 \pm 1.6 \\
\text { CRF: } 6.5 \pm 1.5 \\
\text { PRF: } 2.9 \pm 1.6 \\
\text { CRF: } 2.3 \pm 1.3 \\
\text { PRF: } 3.5 \pm 1.3 \\
\text { CRF: } 2.4 \pm 1.1\end{array}$ & $3.1 \pm 0.8$ & $\begin{array}{l}\text { A statistically significant reduction in back pain was found } \\
\text { when comparing post-procedure are preprocedure } \\
\text { scores for } P R F(P<0.001), C R F(P<0.001) \text { and control } \\
\text { groups }(P<0.001)\end{array}$ \\
\hline $\begin{array}{l}\text { Van Kleef et al } \\
\text { (24), 1999; The } \\
\text { Netherlands }\end{array}$ & VAS & $0-10$ & $\begin{array}{l}\text { Baseline } \\
2 \text { months }\end{array}$ & $\begin{array}{c}5.2 \pm 1.7 \\
2.83 \pm 2.24\end{array}$ & $\begin{array}{c}5.2 \pm 1.6 \\
4.77 \pm 2.5\end{array}$ & $\begin{array}{l}\text { A statistically significant reduction in pain was found in } \\
\text { the intervention group, compared with the control group } \\
\text { two months after treatment }(P<0.005)\end{array}$ \\
\hline $\begin{array}{l}\text { Van Wijk et al } \\
\text { (23), 2005; The } \\
\text { Netherlands }\end{array}$ & VAS & $0-10$ & $\begin{array}{l}\text { Baseline } \\
3 \text { months }\end{array}$ & $\begin{array}{c}5.8 \pm 1.8 \\
3.7\end{array}$ & $\begin{array}{c}6.5 \pm 1.8 \\
3.7\end{array}$ & $\begin{array}{l}\text { A statistically significant reduction in back pain was found } \\
\text { for both those treated with RFA }(P=0.001) \text { and in those } \\
\text { who received sham }(P=0.0003)\end{array}$ \\
\hline Sacroiliac & & & & & & \\
\hline $\begin{array}{l}\text { Cohen et al (15), } \\
\text { 2008; United } \\
\text { States }\end{array}$ & NRS & $0-10$ & $\begin{array}{l}\text { Baseline } \\
1 \text { month } \\
3 \text { months } \\
6 \text { months }\end{array}$ & $\begin{array}{c}6.1 \pm 1.8 \\
2.4 \pm 2 \\
2.4 \pm 2.3 \\
2.6 \pm 2.2\end{array}$ & $\begin{array}{c}6.5 \pm 1.9 \\
6.3 \pm 2.4 \\
6 \pm 0 \\
\text { NR }\end{array}$ & $\begin{array}{l}\text { Statistically significant reduction in pain was found in the } \\
\text { treatment group, compared with the control group (at } \\
\text { one month, } \mathrm{P}<0.001 \text { ) }\end{array}$ \\
\hline $\begin{array}{l}\text { Patel et al (21), } \\
\text { 2012; United } \\
\text { States }\end{array}$ & NRS & $0-10$ & $\begin{array}{l}\text { Baseline } \\
1 \text { month } \\
3 \text { months } \\
6 \text { months } \\
9 \text { months }\end{array}$ & $\begin{array}{c}6.1 \pm 1.3 \\
3.4 \\
\text { NR } \\
\text { NR } \\
\text { NR }\end{array}$ & $\begin{array}{c}5.8 \pm 1.3 \\
4.1 \\
\text { NR } \\
\text { NR } \\
\text { NR }\end{array}$ & $\begin{array}{l}\text { Statistically significant reduction in pain was found in the } \\
\text { treatment group, compared with the control group three } \\
\text { months post-treatment }\end{array}$ \\
\hline
\end{tabular}

BPI Brief Pain Inventory; CRF Conventional radiofrequency NR Not reported; NRS Numerical rating scale; PRF Pulsed radiofrequency; RFA Radiofrequency ablation; VAS Visual analogue scale

base limits the conclusions that can be drawn in the present systematic review.

Of the included studies, very few reported mean differences and SDs of these mean differences. Therefore, quantitative pooling through meta-analysis was not possible; the present study was limited to narrative synthesis. Future work should be encouraged to report data such that pooling is possible, thus enabling conclusions based on the entire body of work assessing RFA for low back pain.

In the present review, pain was the primary outcome assessed. This outcome was used because it was frequently reported and gave a broad sense of improvement or worsening. Many of the included studies only reported statistically significant differences as opposed to predefined clinical improvement. However, in clinical practice, the end goal is for the patient to experience pain relief such that they can return to their daily tasks; a level of pain relief that may differ from the level of pain reduction required to achieve statistical significance. However, these clinically relevant outcomes were not reported in any of the studies identified.

The evidence supports RFA as an efficacious treatment for lumbar facet joint and sacroiliac joint pain with five of six and both of the RCTs demonstrating statistically significant pain reductions, respectively. The evidence supporting RFA for treatment for discogenic pain is mixed and no RCT evidence exists for treatment of the coccyx. However, all the RCT data are short-term $(<1$ year $)$ and do not report 
clinically meaningful pain reduction or outcomes such as ability to complete daily tasks or return to work. Further evidence should be generated before RFA is widely integrated into evidence-based clinical guidelines.

FUNDING/SUPPORT: None.

CONTRIBUTIONS OF AUTHORS: Design of the study (LL, DLL, RS, TN, FC); collection of data (LL, LS, DLL); management of data (LL, LS, FC), analysis of data (LL,LS, FC); interpretation of the data (LL, LS, FC); preparation of manuscript (LL, LS, DLL, TN, RS, ST, FC); review of manuscript (LL, LS, DLL, TN, RS, ST, FC); approval of manuscript (LL, LS, DLL, TN, RS, ST, FC).

OTHER ACKNOWLEDGEMENTS: This work was supported by a grant from Alberta Health. The research herein does not reflect their views or opinions.

DISCLOSURES: The authors have no financial disclosures or conflicts of interest to declare.

\section{REFERENCES}

1. World Health Organization. WHO Technical Report Series: The Burden of Musculoskeletal Conditions at the Start of the New Millenium. World Health Organization 2003. <http://whqlibdoc. who.int/trs/WHO_TRS_919.pdf> (Accessed September 1, 2013).

2. World Health Organization. Chronic Diseases and Health Promotion. World Health Organization 2013. <www.who.int/chp/ topics/rheumatic/en/> (Accessed September 1, 2013).

3. Lawrence R, Felson D, Helmick C, et al. Estimates of the prevalence of arthritis and other rheumatic conditions in the United States: Part II. Arthritis Rheum 2008;58:26-35.

4. Katz JN. Lumbar disc disorders and low-back pain: Socioeconomic factors and consequences. J Bone Joint Surg Am 2006;88(Suppl 2):21-4.

5. Andersson GB. Epidemiological features of chronic low-back pain. Lancet 1999 Aug 14;354:581-5.

6. Office of Communication and Public Liaison. Low Back Pain Fact Sheet. National Institute of Neurological Disorders and Stroke 2013. <www.ninds.nih.gov/disorders/backpain/detail_backpain. htm>

7. Steenstra IA, Verbeek JH, Heymans MW, et al. Prognostic factors for duration of sick leave in patients sick listed with acute low back pain: A systematic review of the literature. Occup Environ Med 2005;62:851-60.

8. Haldeman S, Dagenais S. A supermarket approach to the evidenceinformed management of chronic low back pain. Spine J 2008;8:1-7.

9. Savigny P, Watson P, Underwood M. Early management of persistent non-specific low back pain: Summary of NICE guidance. BMJ 2009;338:61805.

10. Van Tulder MW, Koes BW, Bouter LM. Conservative treatment of acute and chronic nonspecific low back pain: A systematic review of randomized controlled trials of the most common interventions. Spine 1997;22:2128-56.

11. Towards Optimized Practice Program. Guideline for the EvidenceInformed Primary Care Management of Low Back Pain. Toward Optimized Practice Program 2011. <http://nationalpaincentre. mcmaster.ca/documents/LowerBackPainGuidelineNov2011.pdf> (Accessed September 1, 2013).

12. Shealy CN. Percutaneous radiofrequency denervation of spinal facets: Treatment for chronic back pain and sciatica. J Neurosurg 1975;43:448-51.

13. Higgins J, Altman D, Gotzsche P, et al. The Cochrane Collaborations tool for assessing risk of bias in randomised trials. BMJ 2011;343:d5928.

14. Barendse GA, van Den Berg SG, Kessels AH, et al. Randomized controlled trial of percutaneous intradiscal radiofrequency thermocoagulation for chronic discogenic back pain: Lack of effect from a 90-second $70 \mathrm{C}$ lesion. Spine 2001;26:287-92.

15. Cohen SP, Hurley RW, Buckenmaier CC, et al. Randomized placebocontrolled study evaluating lateral branch radiofrequency denervation for sacroiliac joint pain. Anesthesiology 2008;109:279-88.

16. Gallagher J, Petriccione DVPL, Wedley JR, et al. Radiofrequency facet joint denervation in the treatment of low back pain: A prospective controlled double-blind study to assess its efficacy. Pain Clin 1994;7:193-8.

17. Kapural L, Vrooman B, Sarwar S, et al. A randomized, placebocontrolled trial of transdiscal radiofrequency, biacuplasty for treatment of discogenic lower back pain. Pain Med 2013;14:362-73.

18. Kvarstein G, Mawe L, Indahl A, et al. A randomized double-blind controlled trial of intra-annular radiofrequency thermal disc therapy - a 12-month follow-up. Pain 2009;145:279-86.

19. Leclaire R, Fortin L, Lambert R, et al. Radiofrequency facet joint denervation in the treatment of low back pain: A placebocontrolled clinical trial to assess efficacy. Spine 2001;26:1411-6.

20. Nath S, Nath CA, Pettersson K. Percutaneous lumbar zygapophysial (Facet) joint neurotomy using radiofrequency current, in the management of chronic low back pain: A randomized double-blind trial. Spine 2008;33:1291-7.

21. Patel N, Gross A, Brown L, et al. A randomized, placebo-controlled study to assess the efficacy of lateral branch neurotomy for chronic sacroiliac joint pain. Pain Med 2012;13:383-98.

22. Tekin I, Mirzai H, Ok G, et al. A comparison of conventional and pulsed radiofrequency denervation in the treatment of chronic facet joint pain. Clin J Pain 2007;23:524-9.

23. van Wijk R, Geurts JWM, Wynne HJ, et al. Radiofrequency denervation of lumbar facet joints in the treatment of chronic low back pain: A randomized, double-blind, sham lesion-controlled trial. Clin J Pain 2005;21:335-44.

24. van Kleef M, Barendse GA, Kessels A, et al. Randomized trial of radiofrequency lumbar facet denervation for chronic low back pain. Spine 1999;24:1937-42.

25. Reig E, Abejon D, Del Pozo C, et al. Thermocoagulation of the ganglion impar or ganglion of Walther: Description of a modified approach. Preliminary results in chronic, nononcological pain. Pain Pract 2005;5:103-10. 


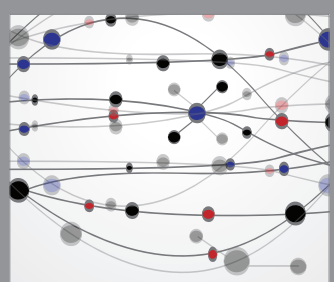

The Scientific World Journal
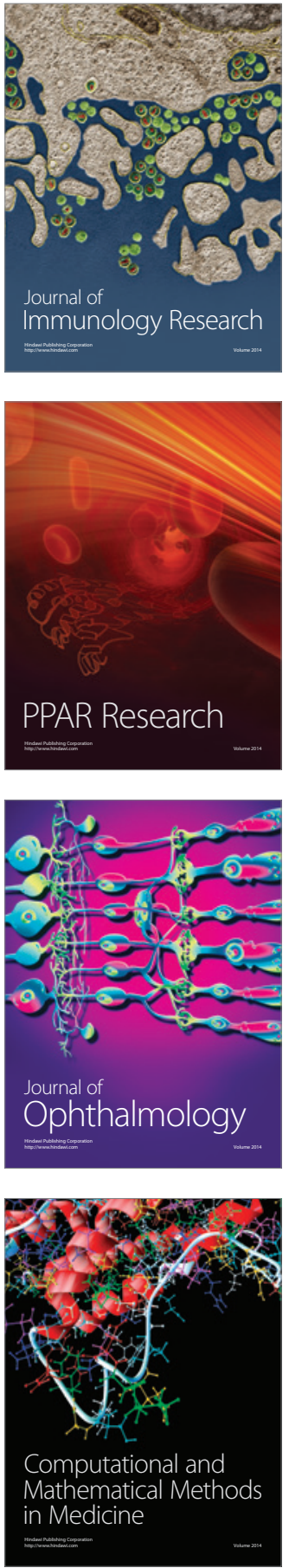

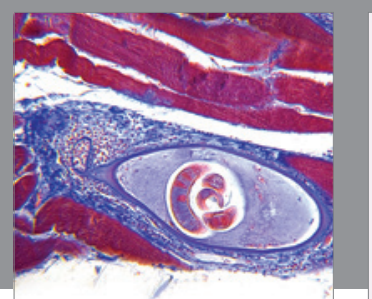

Gastroenterology Research and Practice

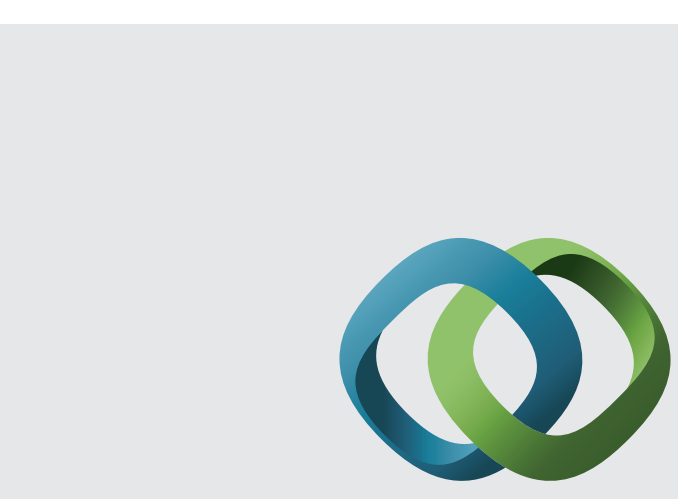

\section{Hindawi}

Submit your manuscripts at

http://www.hindawi.com
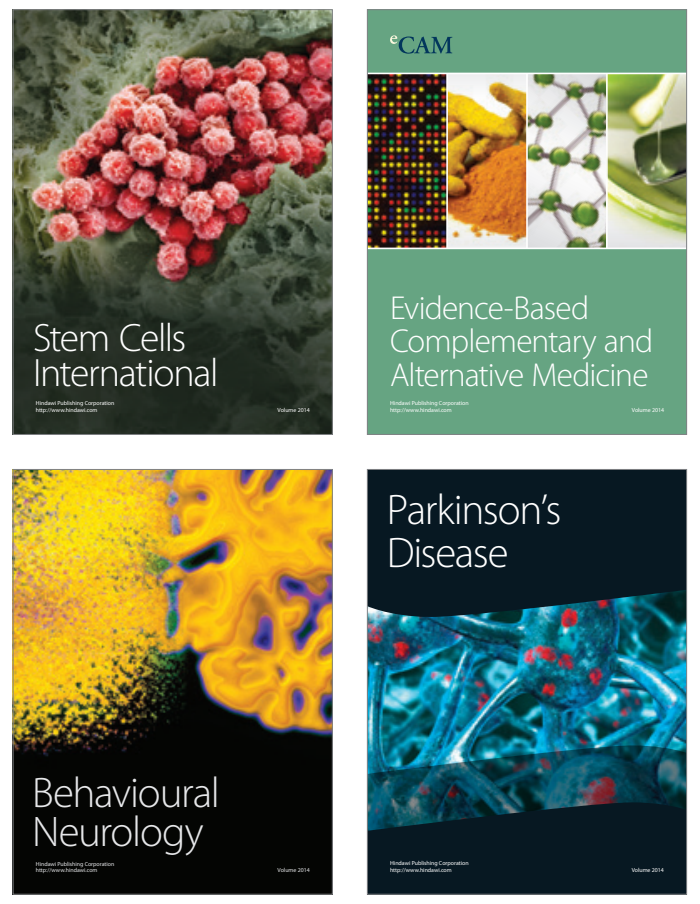
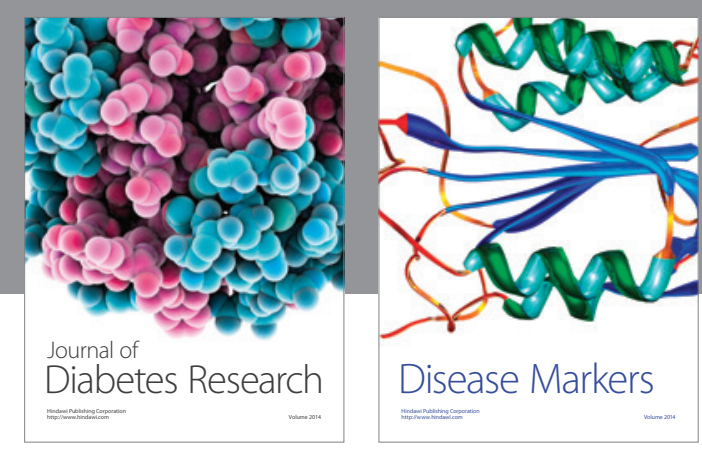

Disease Markers
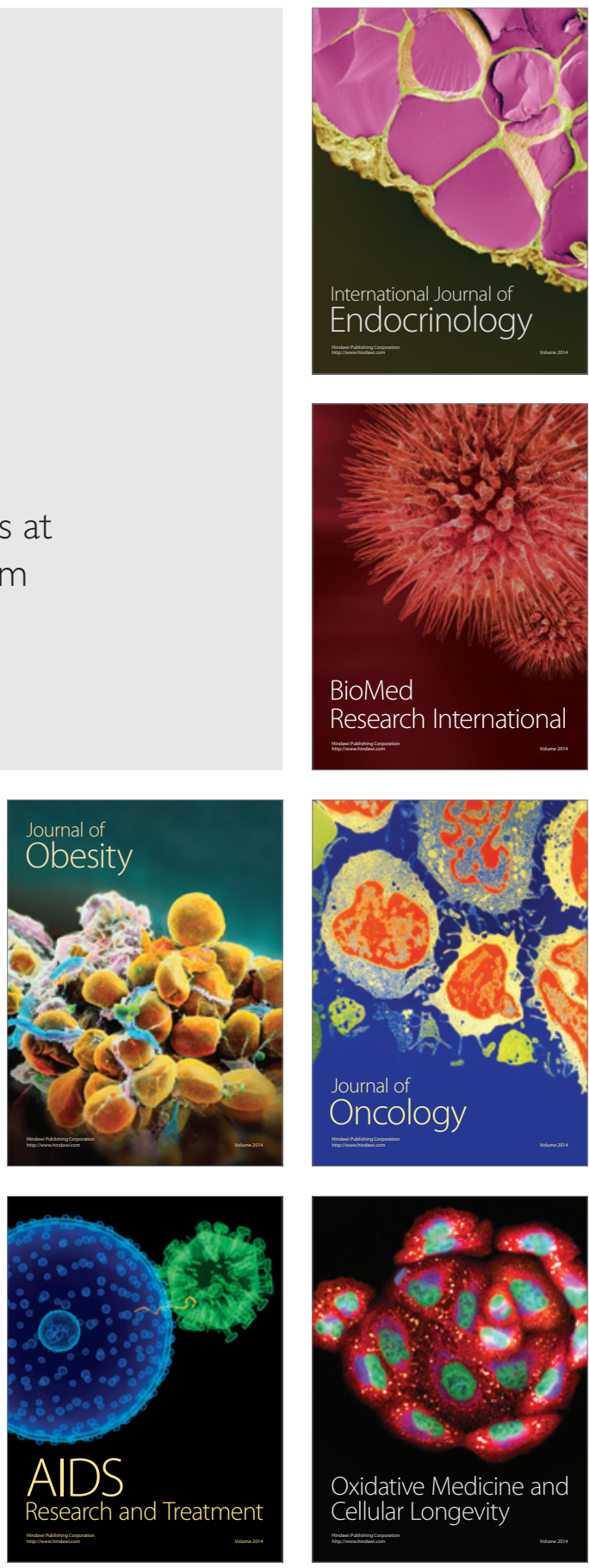